\title{
Art and Technology Playing Leapfrog: A History and Philosophy of Technoèsis
}

\author{
Petran Kockelkoren

\section{Technological mediation} \\ The relation between art and technology
}

Down through history, the relationship between art and technology has assumed many guises. With the present-day rise of new media and technologies, new art forms are appearing which are often situated outside the traditional circuit. The body and its prostheses are highlighted in performances, and the visual arts often link up with industrial design and IC T applications. The formerly sharp dividing line between autonomous and applied art is gradually disappearing. Despite the increasing influence of technology on art, one still speaks of the autonomy of art. The relationship between art and technology is not without friction in contemporary art, but has it ever been problem-free? Contrary to generally held views that ascribe to the artist an almost innate autonomous position over and against cultural processes in which new technologies are adopted, artists actually tend to be accomplices to these social developments. Artists have always played a leading role in appropriating the new ways of looking and hearing that innovative technologies have offered. Technologies that open up new forms of experience have been domesticated and made manageable by artists. It is not an entirely innocent process. In fact, it can best be characterised as a disciplinary process in which the senses are culturally disciplined and the body is conditioned to match. Through the role they play in the embodiment of technology, artists are an accessory to such disciplinary processes.

The central question in describing the relationship between art and technology is that involving the nature and scope of technological mediation, since this is where this relation is fleshed out. Mediation takes place as soon as an artifact articulates our sensory relations with the world around us. Initially, the current sensory disposition is tipped off balance. That event is enveloped in new images and metaphors until a new balance is attained, one 
that incorporates the technology that caused the disruption in the first place. When new technologies are introduced to the public for the first time, a period of decentring commences: a period in which the users do not know what to make of the technology and the world to which it gives access. But it does not take long before recentring strategies are set in motion to domesticate the technology in question. I shall examine the interaction between technological designs and the artistic imagination in more detail.

The thesis that art above all contributes to the domestication of mediatory technologies is a bold one. This thesis is not without its problems, for it runs counter to a cherished image of artistry which holds that the artist adopts an autonomous position vis-à-vis cultural processes. As an independent observer, he exposes the alienation brought on by technology. But I am now claiming that the artist himself, perhaps in spite of himself, is an accessory to strategies of cultural stabilisation. My argument in defense of this thesis boils down to the following: I hope to be able to demonstrate that the notion of autonomy itself is the product of technological mediation. If that is so, the so-called autonomous position outside the cultural flow is untenable, because, in that case, the autonomous position itself is an exponent of a prior disciplinary process. It implies that the more the artist puts up a fight against cultural necessity, the more he complies with it, unless we can redefine autonomy in the light of technological mediation. In that case, autonomy is no longer a point of departure, but rather a result that has to be constantly won from discipline.

\section{Train sicknesses and the embodiment of technology}

A good example of the disciplining of the body and the cultural pathology it entails is provided by the introduction of the train in the 19th century. When people started to travel by rail, there were soon reports of a whole battery of train sicknesses, of which the railway spine became the most famous. It was a controversial diagnosis. On the grounds of spinal damage, though it was difficult to prove, it was possible to claim damages from the insurance companies of the day. This complaint reached epidemic proportions in England in the 1860 s and spread from there to Germany and the United States. Even the Netherlands was not immune. After a few decades the epidemic died down and disappeared from medical discourse, almost without trace. ${ }^{1}$ What was its significance?

At first, the symptoms were described in purely somatic terms. There were reports that railway personnel suffered from eye infections and diminution of vision, and that passengers were affected by miscarriages, blockages of the urinary tract, and hemorrhages. But there was soon a shift to mental disor- 
ders. A Bavarian physician, for instance, wrote: "Travel with some steam engines should be prohibited for medical reasons. The rapid movements will produce mental disturbance. Rail travellers will succumb to brain damage, or 'delirium furiosum'" (Schivelbusch 1977, 113). Railway disorders proliferated in the psychiatric domain. Siderodromophobia was one of the more exotic variants, referring to the general disorientation accompanied by physical discomfort that seems to have affected the first rail passengers en masse.

What happened can best be described using a cultural historical interpretation of corporeality. The body is not some universal substratum on which cultures graft their different linguistic attributions of meaning from above, as it were. In contrast, the senses are prone to historical fluctuations. They are constantly in motion because they are the points of anchorage of cultural reeducation. This can be deduced, for example, from a comparison of the sensory perceptions of the first rail passengers with those of less well-to-do hikers of the same era.

The hikers see and hear the wind blowing in the fields of corn, they smell the grain, while the horizon rises and falls to the rhythm of their footsteps. The different senses confirm one another: the hikers see what they smell and what they hear in a harmony of the senses known as synaesthesia. However, as soon as they step into a carriage and the locomotive starts up, that synaesthesia disintegrates. What they smell is not what they see, they hear the rattle of the wheels on the rails, the horizon slips smoothly by, devoid of any relation to their own body. The disorientation that inevitably results has been well described by the poet Victor Hugo, who sent an account of the experience of his first journey by rail in a letter to his daughter: "The flowers by the side of the road are no longer flowers but flecks, or rather streaks, of red or white; there are no longer any points, everything becomes a streak; the fields of grain are great shocks of yellow hair; fields of alfalfa, long green tresses; the towns the steeples, and the trees perform a crazy mingling dance on the horizon; from time to time, a shadow, a shape, a specter appears and disappears with lightning speed behind the window: it is a railway guard" (Schivelbusch 1977, 5556).

What is near flashes by, what is further away seems to revolve on its axis as soon as you stare at it. All the while, the body remains motionless. It took a while to appropriate the new experience, but after a few decades the disorientation and the rail sicknesses it produced disappeared. A new synaesthesia had been established, this time by embodying the train as a moving medium of perception. That process of embodiment could still produce individual traumas, but they were exponents of a collective cultural process of learning. The orientation from a moving train challenges the previous, culturally es- 
tablished habits of viewing. People had to appropriate a new, technologically mediated sensory regime. At first they became decentred, then they learned to recentre themselves through the simultaneous embodiment of the train. Such stabilisation processes are not once-off, but keep on recurring as new technologies appear.

New technologies and the revelatory experiences they promise are often first explored by artists and presented to the public in the form of artistic events and fairground attractions. At any rate, that is what happened with the train. The World Exhibition held in Paris in 1900 included an attraction that imitated the sensory disorientation of the train. The members of the public were put in imitation compartments and landscape scenes were unrolled opposite them. These had been painted on three layers differing in height, one behind the other, representing the foreground, medium distance, and background, respectively. Each of these panoramic scenes was unrolled at a different speed; the one at the front relatively quickly, the one in the middle more slowly, and the one at the back very slowly. The simulated journey followed that of the famous Trans-Siberian express from Moscow to Peking and lasted forty-five minutes. Simpler versions, using a smaller number of rolls, were presented at village fairs. Some of them lasted two hours (Hyde 1988). Artists often worked as the accomplices of fairground entertainers as the painters of these rolls. People stared at the exotic panoramas and, in doing so, appropriated the art of perceiving in motion.

The industrial revolution was also an artistic challenge. The Impressionists and Post-Impressionists already included industrial objects in their idyllic canvases. Monet's locomotives, wreathed in clouds of steam, are legendary. The founder of Orphism, Robert Delaunay, painted airplanes with revolving propellers, and on more than one occasion he tried to paint a helicopter view, but from the top of the Eiffel Tower. Futurism pounced on the speed of the new means of transport. Just before the First World War broke out, Giacomo Balla and Umberto Boccioni painted moving scenes from speeding trains and cars. The Futurists did not confine themselves to orderly exhibitions, but they also organised rousing lectures and tumultuous Futurist theatre events in the big industrial cities of Northern Italy.

Although the fair and the theatre have been described as refuges from cultural conditioning, they were actually the reverse: they functioned as cultural normalisation machines par excellence. Processes of cultural appropriation of this kind have taken place in an unbroken succession all through history. At a recent fair near my home on the German border, there was a centrifuge and a pulsating cabin that promised a blood-curdling plunge on a virtual rollercoaster. The widespread distribution of phenomena of this kind throughout 
the centuries means that human sensory perception is historically determined from start to finish. Our perceptions have always been completely mediated by technology. There is no underlying, original substratum. There is only a permanent oscillation between decentring and recentring, with mediatory technologies as the engines of change.

\section{Natural artificiality}

\section{Human ex-centricity and its entanglements}

We handle historical mediations by embodying technology in a process of decentring and recentring. In trying to clarify the relationship between mediation and decentring/recentring, I shall fall back on the philosophical anthropologist Helmuth Plessner. Plessner explained this complex of phenomena in terms of his philosophy of human "ex-centricity" (Plessner 1928). People are "ex-centric" because unlike animals, they do not coincide with themselves. They distinguish themselves from animals by their very capacity to distinguish themselves from animals. They do not want to be confused with them. They are able to distance themselves. They can even stand beside themselves and look over their own shoulder, as it were, at everything they do. People are outsiders in relation to themselves. So human ex-centricity also entails their mediated access to the world. Because of their involvement at a distance, people do not have direct access to the world around them. Their senses are always culturally mediated by language, technology and art. People are "naturally artificial" by virtue of their ex-centricity. Technology cannot alienate people from their naturalness, because they are already alienated by virtue of their very condition. Language, technology, and art teach people how to articulate and even to celebrate their ineradicable alienation.

Mediation and decentring/recentring are intrinsically related to one another because they are both rooted in human ex-centricity. Ex-centricity, not coinciding with oneself, is an a priori fact of the human condition. People cannot become ex-centric, they already are ex-centric. Plessner himself was very reticent on the question of the historicisation of ex-centricity. He was afraid that it would open the door to a linear model of cultural development, from a primitive state of coinciding with oneself to a modern state of decentred existence. According to this kind of model, earlier cultures, in which artisanal mediations dominate, are "primitive" by definition, while more decentred cultures, in which machines and automata mediate, are considered, for that very reason alone, to be "more developed" or even "more rational". Plessner would have nothing to do with this kind of deprecation of traditional cul- 
tures, because they no more coincide with themselves than we do. He never tired of driving home the point that even prehistoric humans lived a decentred life. However, one of Plessner's followers, Lolle Nauta, broke Plessner's embargo on the historicisation of ex-centricity by claiming that human excentricity is both an a priori fact and a historical voyage of discovery. That voyage of discovery presupposes successive, technologically mediated processes of decentring which, in turn, are only possible at all by virtue of that ex-centricity (Nauta 1986, 64). In this view, technological mediations have at least the status of being one of the driving forces of the process of human selfdiscovery.

For the time being, we know enough about the inextricable connection between technological mediation and the processes of decentring and recentring to be able to continue our analyses of historical mediations. However, an important question that has to be raised in order to clear the way for an inquiry into the relation between art and technology is the question of whether or not technological mediations have a determinant character. It would be extremely naive if we suddenly regarded history as being entirely caused by technological mediations. A historicisation of the idea of human ex-centricity must not be allowed to boil down to changing signs. Cultural history has been identified with the history of ideas for a very long time. Replacing the primacy of ideas by that of technology would be tantamount to exchanging one determinism for another.

There is no a priori reason why technologically mediated processes of decentring and recentring should necessarily move in the direction of increased rationalisation or the development of higher values. Human ex-centricity means that technological mediation plays an important role in every opening up of reality in a broad historical diversity. New technologies open up the worlds that correspond to them and require the development of corresponding images and meanings. They need not necessarily be mutually compatible, nor need they develop in the direction of an ultimate truth.

\section{The co-evolution of technology, image and meaning}

Cosmologies derive their validity and its limited scope from the mediatory technologies with which they are entwined. In retrospect, Marx turns out to have been right after all in claiming that the infrastructure (the relations of production) determines the superstructure (the world of ideologies), but he is only right to a limited extent. In the present-day conditions of technological pluralism, we no longer espouse the linear causality that was a characteristic of the era in which Marx lived. New technologies do not "cause" new ideas. 
Marx's thesis that the relations of production determine ideas is in need of differentiation. For that purpose, we can make good use of the notion of technoèsis.

The capacity of technology to open up reality and to give shape to culture has been called technoèsis by Roy Ascott, philosopher of the new media (Ascott 2000). Noèsis, a word of Greek origin, means "act of cognition". In this view, knowledge is considered not as passive registration, but as an active turning towards the object of knowledge. That activity may also entail technological mediation with the requisite corporeal adjustments. So technoèsis is an act of cognition via technology or the technologically mediated formation of images and conferral of meaning. ${ }^{2}$ In other words, we learn to perceive and to attach words to what we perceive in a culturally conditioned way through technology. The category of technoèsis covers those phenomena that occurred at the introduction of the train, for example. Contrary to what Marx thought, technoèsis does not lead to massive alienation. After all, in the philosophy of mediation, there is no natural substratum to fall back on. Recentring does not lead us back to some unspoiled, primeval state, but at most, it brings about a temporary state of equilibrium in a process of technological mediation.

Instead of embracing a naive technological determinism, we need to situate technoèsis in a manifold co-evolution of technologies, images and ideas. The technological design process is driven by interested groups that gradually have to create a basis of support for their approach and have to recruit scientific and economic aid for that purpose. During its development, a new technology is surrounded by numerous visions of the future and guiding metaphors that only gradually crystallise into a presentable technological product. The product still has to stabilise after its introduction on the market. There is no one best way of technological adaptation. What we see instead are processes of interlocking design and stabilisation. Every technology is surrounded by a nimbus of images and metaphors that guide the development of that technology and must eventually help to domesticate it. ${ }^{3}$ In the meshes of that process, we seek the space in which artistic imagination ties in with technological design.

The contribution of artists is not an intervention from outside, nor does artistic design only point the way in processes of domestication after the event. The formation of artistic images and technological design evolve in parallel. Images, technologies and even scientific theories emerge in a social process, and that process is not marked by monocausality. That is why I prefer to speak of the co-evolution of technological design, the formation of images and the conferral of meaning - in other words, technoèsis. It is not a deterministic process. It allows room for artists to manoeuvre. 
A weak and a strong variant are possible in accounts of historical cases of technoèsis. We have already considered the example of what happened when the train was introduced. The weak variant only indicates how new metaphors are deployed. The train that speeds through the night without ever stopping at the stations that flash by soon appeared as an archetype in psychoanalytical dream interpretation, a discipline that owes its vocabulary to the 19th-century metaphor of the steam engine and hydraulics. Without them, thinking in terms like emotional overload and the multi-layered model of the personality (in which deeper layers are penetrated and dragged up to the surface for rational inspection) would not have gained validity.

Piet Vroon and Douwe Draaisma (1985) present the history of psychology as an alternation of guiding metaphors consistently derived from dominant technologies: from the clock or timepiece, via the steam engine, telephone switchboard, radio and radar, to the calculator and the computer. The different metaphors cover theoretical areas that are mutually exclusive, but outdated metaphors are occasionally brought back into use to refer to newly discovered areas. It might also be the case that metaphors derived from older technologies cover a more adequate theoretical field than more modern ones for certain evolutionary layers of the brain. So metaphors and entire figurative languages do not succeed one another historically in a straight line, but overlap.

However, this kind of loose, more associative version of history is not yet sufficient for us to be able to speak of technoèsis in a general way. We are discussing the cultural manipulation of sensory perception, and in that case, it is not enough for technologies merely to appear as topics of conversation. We must try to find cases of the genesis of key philosophical concepts through mediatory technologies in which those concepts then come to apply to those technologies in a domesticating way. The dominant philosophy of a particular period should be articulated by metaphors provided by the technological instruments and equipment of that era. That is the strong variant we shall explore further.

\section{Autonomy as an exponent of technological mediation}

The "autonomous subject" as a product of linear perspective

A strong example of technoèsis is the birth of the autonomous subject in the Renaissance. This example has been widely discussed ever since the art histo- 
rian Erwin Panofsky tackled the theme of the historical genesis of the autonomous subject. The notion of autonomy defines the individual as the source of meaning and as the point of accountability of experience. This view of autonomy, according to Panofsky (1991), depends directly on the practice of perspective painting in the Renaissance. Panofsky argued that linear perspective was not only the formalisation of a natural use of the senses, but rather introduced a new sensory regime to replace the medieval variant. The rules for drawing in linear perspective were first drawn up in practice by Filippo Brunelleschi in 1425 and laid down in the treatise on painting De Pictura by Leon Battista Alberti, which was published in 1435/36. Most Westerners have been familiar with the organisation of our field of vision according to the regularity of linear perspective since infancy. What we perceive is arranged within a clearly delineated frame, with the eye focused on a single, central, disappearing point situated on the horizon. ${ }^{4}$ How does that arrangement of the picture affect our orientation to the world around us?

Through the application of linear perspective, the world is transformed into an external scene, while in the same movement the viewer, who was initially a part of it, is dragged backwards out of the picture and turned into a remote spectator. The technique of perspective mediates between the spectator and the natural scene; the two poles are generated as opposites through that very process. At some point, the spectator allows himself to be portrayed as a large figure against a landscape in the background. A new sensory regime has taken root. The autonomous subject is born. Descartes signed that birth certificate with the well-known dictum: "I think, therefore I am", thereby proclaiming the autonomy of the subject. According to Panofsky, there is a direct connection between the technique of perspective painting and the later Cartesian view of the subject.

Panofsky's theory of the cultural genesis of the subject was subsequently embraced by philosophers who drew attention to the alienation produced by technology. In their view, it is hardly surprising that we have been saddled with an environmental crisis. ${ }^{5}$ A detached subject was created in the Renaissance. Those circles always put the blame on Descartes, claiming that, for a Cartesian subject, nature can only appear as an external scene, no more than a stock of raw materials waiting to be plundered. Although their accusations came rather late, they view the environmental crisis as being inextricably tied up with the Renaissance imposition of perspective on nature. According to them, technological alienation only became really irreversible with the introduction and rapid dissemination of the camera. This device makes automatic what initially had to be represented separately each time. The consequences are disastrous: this piece of equipment makes the world available in an end- 
less series of snapshots. In this way, an authentic anchoring in a site is irrevocably lost. Once the reality of events is equated with their capacity to be photographed, alienation becomes virtually unstoppable.

\section{The material conditions of the history of ideas}

Criticisms of this view have been put forward by a new generation of followers and critics of Panofsky, one of whom is Jonathan Crary. Before praising Panofsky, we have a bone to pick with him first. We were trying to find an example of the material conditions of the genesis of meaning, and came across Panofsky on our quest. But the inclusion of Panofsky as a fellow traveller is misleading in a certain sense. Panofsky did argue that the practice of perspective painting laid the foundation for the autonomous subject, but he was not at all interested in the material conditions of technological mediation.

Panofsky saw the introduction of perspective not in connection with new technologies, but as an instance of the geometrification of the picture of the world. He was a Neo-Kantian who conducted a historicising investigation of how the senses in the Renaissance were subjected to a new sort of a priori rationalism. Moreover, it was precisely on that score that he came in for a good deal of criticism. He was accused of explaining the origin of painting with a linear perspective in terms of Descartes's much later epistemology, in order to present that epistemology as an exponent of the linear perspective. He was thus accused of something that historians never pardon - an anachronism. This is due to some extent to the fact that Panofsky exclusively practised the history of ideas. He was barely interested in the material conditions under which that process of geometrification could take place. A better understanding of the technological mediations at work might clarify the connection between a technique used in producing images (the linear perspective) and epistemology (the notion of the autonomous subject). Only then are they treated as co-evolving phenomena. So an appeal to Panofsky calls for a shift of theoretical ground. Panofsky's account only becomes forceful after it has undergone a materialist turn. Jonathan Crary has taken the first step in that direction.

Crary (1992) refutes those analysts who claim that the camera is an unbroken continuation of Renaissance perspective, and that there is no historical transformation between them. Renaissance linear perspective already came under fire at the beginning of the 19th century and was even replaced by a different sensory regime. The development of the Renaissance perspective, Crary argues, was dependent on the instrument of the camera obscura. This is a device that admits light through a small opening (often covered by a glass 
lens) into a box or darkened room to project an image of the outside world onto a surface opposite. The minuscule opening faced the outside world; the projected image was upside down. This device provided the dominant metaphor for how the eye operates and led to the formulation of optics. Moreover, it offered the metaphor of consciousness as an inner world in which the outside world is represented. Most historians have considered the later camera to be no more than a technically improved version of the camera obscura. In view of this technological continuity, the image of consciousness did not change very drastically in the intervening period. The autonomous subject of the Renaissance is thus credited with persisting down to the 2oth century.

Crary sees things differently. New gadgets appeared at the start of the 19th century, and they not only required different ways of looking but also generated different kinds of subjects. The 19th century is filled with clever viewing devices and toys, such as the thaumatrope, zoetrope, kaleidoscope, and stereoscope. All of these gadgets differ from the camera obscura in that the latter installs an uninvolved observer who is condemned to passive watching, as if the retina functions solely as a legible projection screen, while all the other devices involve the senses, including sight, in a physical way. Each of them requires an active contribution by the body to the act of perception. The different kinds of active physical involvement are then taken to correspond to an equal diversity of types of subject. At any rate, it is to the beginning of the 19th century that Crary dates the birth of the scientific observer who employs a broader sensory register in his perceptions than the Renaissance observer who was limited to a visuality that simply registered what he saw.

What actually happened in the 19th century was the incarnation of the Renaissance subject. The subject created by the application of linear perspective is an abstract, universal subject (a mind's eye), instantiated in each individual, it is true, but interchangeable with any other at the same time. The 19thcentury subject, on the other hand, is diverse and embodied. Subjectivity is diversified among the different senses, and distributed to different, unique, bodily centres of accountability, whereas the Renaissance canon of vision deliberately rejected physical differentiation: people were distinguished from one another precisely by their mental capacity or spirit.

The perspectivist view was dependent on the camera obscura, Crary claims. But by exclusively concentrating on the camera obscura as a mediatory instrument, he follows Panofsky in overlooking a number of materially mediated disciplinary strategies. Perspectivist vision was initially practised using a pane of glass to draw on and a visor to facilitate vision with one eye (Wachtel 1995). These material aids ensured that the painter kept his head still 
and that he maintained a distance from his object because the pane of glass separated them. In this way, the artist's body was disciplined, which meant at that time that the body was removed from notice as much as possible. The subjects formed in this way were purely mental subjects. At the same time, the body - like any other object - was subjected to the perspectivist gaze, or rather, it was first turned into an object by that gaze (Romanyshyn 1989).

\section{Anatomy theatres and panorama buildings as centring machines}

To popularise the objectifying view of the body, anatomy theatres were set up in almost every European capital. Spectators, or people who were compelled to be spectators in them, could pay to watch anatomical dissections being conducted. Those anatomy theatres imposed a perspectivist view of the body through their architecture alone. The circular anatomy theatre in Uppsala, for instance, which was completed in 1663, was surmounted by a large dome beneath which a circle of windows admitted daylight. That light fell on benches arranged in descending rows; in the middle was the dissecting table. Maps of the world were attached to the wall behind the uppermost row of benches to enable the visitors to get used to the new bird's-eye view of the world. If people turned their backs on these maps, they could literally look down upon the anatomical section below. All the anatomy theatres looked like ex-centricity embodied in architecture. Those who did not frequent the anatomy theatres could still be confronted by some of the numerous paintings on the theme of the anatomy lesson. ${ }^{6}$ Art and theatre had already played an important role in the Renaissance in popularising the new modes (or should I say fashions?) of sensory perception.

Once one is aware of these often-frivolous forms of education and discipline in the margins of culture, there is no need to be surprised that the 19th century presented the same picture. One difference from the Renaissance, however, was that the theatres and the emerging popular fairs now served to incarnate the subject. Stereoscopes and similar devices could be found in bourgeois drawing rooms. These viewing games mobilised a new type of bodily involvement on the part of their users. The London Stereoscopic Company, established in 1854, set itself the target of "a stereoscope for every home". Soon afterwards, the first train appeared on the scene. The body was bombarded from all sides, and had to learn to shake off its Renaissance habits. To that end, fairground attractions of all kinds sprang up in the wake of the train, and illusionism was the rage in theatres everywhere.

The 17th-century anatomy theatres were succeeded by the panorama buildings of the 19th century in terms of both architecture and function. De- 
centred people practiced centring themselves in a landscape in the cylindrical panorama building with a diameter of 40 meters. Dozens of them sprang up in Europe, in the capitals and along the coasts. The dimensions of the buildings were standardised on the model of the Panorama Hittorf, set up in the Champs-Elysées in Paris in 1838. Consequently, the landscape paintings were interchangeable and could travel. That these really were centring machines can be seen, for instance, from the Great Globe (1851/62) in Leicester Square, London. Inside the gigantic globe, a four-storey staircase was constructed from which the interior could be viewed - an inside-out model of the earth. The continents could be taken in at a glance from the centre of the globe (Bätschmann 1984). Panorama Mesdag in The Hague, which first opened its doors in 1881, has been preserved down to the present. The panorama it presents is an artificial dune landscape on the coast of Scheveningen; the real landscape could be seen a stone's throw away for nothing, but people felt lost in the face of the sky and the sea. The fact that they queued up to see the same landscape inside the panorama confirms the idea of a centring machine.

\section{The erosion of autonomy}

Crary has little to say about these kinds of popularising processes of embodiment. He does have a lot to say about discipline and normalisation, even suggesting that it all amounts to exploitation of the workers. He acknowledges his debt to Foucault on several occasions, but fails to get to grips with the materially mediated production of bourgeois bodies. He treats the camera obscura and its 19th-century family of visual instruments exclusively as a topic of conversation for philosophers. He leaps straight from a few isolated instruments to key philosophical concepts among individual philosophers (slipping up here and there in the process). ${ }^{7}$ We have to use our own imagination to conjure up the parallel processes of embodiment with their technoètic dissemination. Crary does offer a lot of evidence to support a technoètic historiography, but his own contribution to it requires rewriting in that direction. That would add more cogency to his claims.

The Renaissance subject acquired form through the techniques and practices of linear perspective and the camera obscura. The techniques of linear perspective made the subject a detached observer. The camera obscura equipped the subject, metaphorically, with an inner, independent world. That inner world was shaken up when people started to travel by rail. It is no surprise because the sensory regime installed by the Renaissance was aimed at the fixation of the gaze and the freezing of an exterior scene for inspection. The view from the railway carriage imposed very different demands. Howev- 
er, none of the different regimes can claim to present "natural" sense perception or to be more "natural" than the others. People are simply naturally artificial, and artists teach us to live with the fact, for better or for worse.

New technologies are explored by artists for their potential to create images, and are domesticated in the process. At the same time, the same technologies are investigated by philosophers and writers for their metaphorical potential. Technoèsis runs its course. I have thrown some light on the creation of the notion of the autonomous subject as an exponent of that, as well as on its relative validity, throughout all its techno-historical transformations. The notion of technoèsis does indeed appear to be a fertile heuristic guideline for the writing of history, but, to repeat, if I present artists as the accomplices or even the vanguard of normalising and disciplinary cultural practices, what is left of the renowned autonomy of art and artists, especially as it is the very concept of autonomy which provokes the necessary historico-philosophical doubts?

In the Renaissance tradition, the idea of autonomy was projected backwards on to the ideas of classical thinkers like Plato and Aristotle. In this way, the autonomous subject was credited with an eternal existence, as if autonomy were an innate highest good. After tracing that luminous idea back to antiquity, Renaissance philosophers then claimed to have rediscovered it, and drew themselves up in battle order to defend it. Thinkers of the Enlightenment regarded the so-called rediscovery of this idea as a sign of progress in history - or rather, history was defined as rectilinear progress. But now that we are in a position to make the necessary historical corrections, the whole notion of innate autonomy and progress turns out to be no more than an exponent of the mediations of the time. The retroprojection of these ideas into classical antiquity was used to legitimise the regime of central perspective that was striving to achieve dominance. At the same time, however, a number of rival sensory regimes were operative that were excluded or relegated to the sidelines by this strategy of legitimisation. Those alternatives were no less valid in themselves. ${ }^{8}$

If we rewrite history in terms of technoèsis, it not only becomes possible to trace the Renaissance back to its material technological conditions, but the same also applies to the alienation thesis from the second half of the 19th century to the second half of the 2oth, and to the idea of technoèsis itself. The idea of alienation and the correlative claim of the original nature of man are exponents of industrial mass production with its risks of cultural leveling. The ideas of natural artificiality, technological mediation and technoèsis then become exponents of the technological pluralism of the second half of the 2oth century. Since a technological pluralism constantly preserves a certain degree of decentring, this furnishes the historical context for the idea of human excentricity. 
The huge question now facing us is that of whether or not it is possible for autonomous artists to maintain a critical relationship to the multiple disciplining processes from which autonomy and other concepts arose. According to the Romantic view, artists expose technological alienation from an independent position. Is this viewpoint valid now that we have disposed of the idea of alienation, as Plessner did? And what does it mean if the artists themselves are completely caught up in rival technological mediations?

\section{Autonomy over and against mediation}

The conquest of autonomy

It will have become obvious by now that the concept of autonomy is open to a variety of interpretations. It can stand, among other things, for an allegedly inalienable property, it can be opposed to alienation in the form of originality, and it can mean that a person has to win an independent position over and against heterogeneous forms of discipline. The autonomy of art and of artists means something else in all those cases.

Under the present conditions of technoètic pluralism, people are exposed to heterogeneous forms of discipline. People are free to regret the fact if they so choose, but it also entails opportunities for unprecedented freedom. At any rate, it resolves one of Foucault's profound problems. Foucault investigated normalising and disciplinary social processes. He paid attention both to the power of language and naming, and to the material forms of influencing behaviour. For instance, he pointed out how architecture forces people to move in a certain direction. He was not the first to historicise corporeality - Freud, Wilhelm Reich, Norbert Elias and J.H. van den Berg were predecessors or contemporaries who developed more or less reliable alternatives - but Foucault spoke in the name of philosophical resistance. Culture is not merely written on the body, externally as it were, while the body is a substratum that remains the same all the time; on the contrary, the body is socialised right down to its deepest sensory level. However, if discipline demands the whole of the body, from which position can one still rebel or even protest against current disciplinary practices? Does the body still hold on to a remote place of refuge?9 Foucault had his doubts, but I am tempted to see the salvation of autonomy precisely in the pluralism of sensory regimes.

With the erosion of the claims of the Renaissance perspective to universal validity, and with the refutation of the pathos of the Romantic resistance to alienation, space is created for a critical deployment of human ex-centricity. It is precisely in the friction between the heterogeneous forms of discipline 
that arise from that ex-centricity that the possibility arises of adopting an autonomous position vis-à-vis any regime. People express themselves by means of mediatory technologies, but they must also reclaim their autonomy from the embodied technologies by virtue of their ex-centricity. We all win our autonomy from the spectacles, artificial hips, pacemakers, mobile phones, cars, televisions, etc. that have become a part of us. And at the same time we owe our current notion of autonomy precisely to technological mediations of this kind. That is the double bond of natural artificiality. Every technological piece of equipment contributes to the definition of its user. For instance, we may well wonder what kind of subject is installed by television. William Uricchio from the University of Utrecht is currently performing research in that area. In disagreement with Crary, he claims that television is the successor to the camera obscura and that this appliance continues to produce the Renaissance subject, whether we like it or not (Urichio 2000). He may be right. But, fortunately, we simultaneously undergo the influence of numerous other devices that prescribe something else.

Artists are also exposed to such heterogeneous influences. They explore the access to reality that devices offer by trying out a new visual language for it. They do not create their art on the basis of some deep, essential core that is less accessible to ordinary people, and from where they can resist the alienation of the masses. Plessner's philosophy of ex-centricity shows that people do not have any essential core at all. They have to turn themselves into what they are by artificial means. People are alienated by their very nature. They are, paradoxically enough, constitutionally lacking a foundation. By virtue of that, autonomous art can only be that form of art which places a walkable platform above our constitutional lack of foundation. It can do so by testing the mediations we require for that. In that way, art is an accomplice to the diffusion of conventional forms of disciplining, but at the same time it represents a critical potential to resist them.

What is the nature of that critical potential? What is its anchor point? The Renaissance tradition has passed down to us a view of aesthetics according to which it is merely a question of formal characteristics that can be distinguished in an exclusively visual pattern. But that very notion was itself technologically mediated and was based on a particular sensory regime that prescribed a reduction of the senses to the visual. If we give pride of place to technological mediation, criticism must consistently focus on the specific point of contact between technology and the senses, because it is a question of repeated embodiment and the corresponding adequate technoèsis. That is why we have to start and end with the senses and their mediated nature. 
Many artists experience the medium in which or with which they work as an obstacle to be overcome. They do not want to be hindered by the material they use. Most of the artists who come to the university for technical support in overcoming those material obstacles delegate the task to engineers, so that they only need to concern themselves with the "artistic" side. This establishes a division of labour that turns the artist into a visionary walking on air, and burdens the engineer with a rather uncreative task; after all, he is only made responsible for the practical implementation of the artistic idea. The capacity of technology to shape culture is entirely ignored.

Technology is more than an instrument for the expression of prior images and ideas. Media like the film camera and the video recorder also do more than passively record what appears in front of the lens. For the artistic expression to do justice to the medium deployed, the preconceived functional aspect of the technology must be investigated and surpassed with the help of the media used. But only too often, the limitations of the equipment used determine the visual idiom that it produces, without itself being thematised. The device is embodied, disappears from the field of attention, and is neutralised as a frictionless "go-between". The artist can then make a free choice from the media at his disposal for the implementation of his preconceived ideas. All the same, investigation of the technological mediation itself is not without precedent. The 19th-century discussions of the verisimilitude of stereoscopic images show that mediation was noted, and even exploited by artists and scientists. My source here is Instruments and the Imagination by Hankins and Silverman (1995). Among other things, they offer an epistemological analysis of the mediation of perception by the stereoscope.

In the 19th century, the discussions on the merits of instruments of perception were couched in terms of fidelity to nature. Both the scientific and the popular views of the stereoscope shared the background of natural theology that was widespread at the time. In that view, God had designed the human senses perfectly for the correct perception of nature. The stereoscope was initially welcomed as the instrument that was an improvement on the perspectivist representation of nature on a plane surface - whether in paint or in photography - in terms of verisimilitude. All the same, right from the outset, there were opponents who pointed out the mediated character of every perception and the inevitable transformations that are the result of it.

A discussion of the distance between the camera lenses that made the two photographs required for stereoscopy is illuminating. If fidelity to nature is regarded as the norm, the distance between the lenses must correspond ex- 
actly to the distance between a pair of human eyes. That norm was indeed vigorously defended by the orthodox advocates of natural theology. Any deviation from it was treated as heretical "distortion", a term which only has meaning in relation to a standard, "natural" way of looking that was considered to have been given by God. At the same time, however, others saw ways of using the stereoscope to expand the field of human vision.

The success of stereoscopy proceeded parallel to that of the earliest photography. Both technologies appeared to be able to guarantee the authenticity of what was shown. But photographers in particular engaged in fierce discussions of what the medium could contribute to visual inquiry. In landscape photography, for example, cameras placed at a distance from one another were used on a large scale for stereoscopy. The effect of the artificially increased distance between the lenses on the stereoscope was that the representation of the landscape displayed much more depth and the mountains were apparently much higher than was possible with a "natural" distance between the eyes, but at the same time the landscape seemed to have been miniaturised and imprisoned in a viewing box. Hermann vom Helmholt nevertheless elevated his invention, telestereoscopy, to the status of a scientific research instrument.

The stereography of the moon by Warren de la Rue in 1858 was the climax of artificially heightened relief. The moon always presents the same side to the earth, so that we can only guess about the relief of its surface. However, if the moon is photographed twice with an interval several months in between, a difference in standpoint is created between the two moments. This made it possible to exploit the effect of the libration (the wobble of a heavenly body) of the moon, since the libration also causes a slight difference in the angle of exposure. Consequently, the relief was heightened in stereoscopy with photographs taken at large intervals from one another. De la Rue compared the effect with the vision of a giant whose eyes are thousands of miles apart. He defended his method as follows: "We may be well satisfied to possess such a means of extending our knowledge respecting the moon, by thus availing ourselves of the giant eyes of science". With these words De la Rue appeals to Sir John Herschel, who added: "Lunar stereography entails a step out of and beyond nature". ${ }^{10}$

The step "beyond nature" can be understood in two ways: it may be regretted as a loss of authenticity, as the orthodox view had it, or it may be welcomed as a calling into question of the authenticity of every standpoint. In the latter case, the "natural" way of looking appears fortuitous, and the distance between the eyes of a human being interestingly becomes interchangeable with that of a fly or a giant. The bottom line or the absolute benchmark in 
something "natural" thereby ceases to have any meaning and disappears. That is exactly what happened in the discussions in the 19th century. Initially, natural theology functioned as the benchmark, and it clung to the unmediated body. But that insouciance was belied in the discussions of mediation. Mediation became an interesting object of inquiry in its own right.

\section{Autonomy in new media}

Anyone who takes photographs today or makes use of other image mediators has to justify the type of mediation used in his visual idiom. Autonomy shows itself in a critical handling of such mediation. Unfortunately, many artists today are guilty of an instrumental view of media, in which the media are seen as neutral means of recording; people are simply free to choose from them, depending on the ease of representation and transmission. In the meantime, however, their own practice often belies the way they put it into words. With the rise of new media and technologies, new art forms have emerged. Fine art is linked with industrial design, website design, architecture and spatial planning, or it characterises itself in performances, street theatre and pop culture.

The new appraisal of artistic exploration of technical mediation means that the mediating technologies themselves can move into the limelight. Perhaps the main reason for the awkwardness of the relation between art and technology is the principle of "remediation". New media have the tendency to swallow the older media, to transform them, and to recapitulate them in a different form (Bolter and Grusin 1999). The talking film was a combination of the telephone, camera obscura, magic lantern, camera, and phenakistoscope. The typewriter went through several transformations before it was absorbed by the word processor. The personal computer repeated the typewriter before bringing photographic and film editing on to a different plane.

The phenomenon of remediation is not new; it already occurred when writing was replaced by printing. But today the remediations are tumbling over one another. Old films are transferred to video and then broadcast on television; video is replaced by DVD, television news by the Internet, and so on. In each transformation that takes place, however, specific characteristics of the older media are lost. One of the first explorations of video as a medium showed a man trying to escape from the television set; it looked like someone trying to escape from a box. When this video is projected on to a wall via a beamer, the whole effect is lost. A video show cannot match the rattling of the film projector in the intimate darkness of the cinema. That is why it is necessary to keep not only the film rolls and videotapes but also the equipment for which they were made. Now that generations of equipment succeed one an- 
other at such a fast rate, and rival systems are often in circulation, it is no easy task to keep and show medium-specific works of art.

Remediation does not only apply to the equipment; the embarrassments and contradictions connected with authorship are also a case in point. Nowadays interactive works of art are put on the Internet. They change as a result of the login of the viewer, who thereby becomes a co-author. The medium and the user increasingly define one another. A similar process is taking place in commercial visual communication. It used to be called "applied art", to distinguish it from its élitist counterpart, autonomous art, but nowadays both of them depend on teamwork in media laboratories where they have to take their orders from the same machines and automata. Art is increasingly and ubiquitously becoming an interactive process that can no longer be delimited and isolated. All the same, video artists still sometimes try to preserve the notion of the original creative artist, by signing their videotapes and releasing them in limited issues, for example. However, in that case, they are resorting to rituals of demarcation that were already established by art printing and photography, in spite of the fact that such willful limitations were and are not specific to those media either. Apparently, artists often slip back into outmoded framings of autonomy.

To sum up the results of my analyses: artists are involved in technological mediations and the intrinsically related disciplinary processes. Their autonomy is an exponent of such processes that they themselves have helped to pioneer. There is a Baron von Münchhausen effect in the freedom that they have managed to win vis-à-vis technological mediations, for they do not elevate themselves from some Archimedean point or other outside the flow of mediations, nor from a predetermined core or source of autonomy. They implement their ex-centricity in process, as an intersection of influences subject to economic and political pushing and pulling. The vessel is renovated as it sails. Engineers can launch the offshore process better with the artists as equal partners - after all, art and technology are leapfrogging over one another all the time everywhere. When artists and engineers co-operate, they are-hopefully critical - agents of cultural decentring and recentring processes.

\section{Notes}

1 See Schivelbusch (1976), Luijf (1990), Siemerink-Hermans (1998).

2 The concept "noèsis" or act of cognition was used by Husserl to refer to the intentionality of the consciousness. The correlate of such an act of cognition is the "noèma", that which is cognised. Unlike Husserl's emphasis on pure conscious- 
ness, the term "technoèsis" stresses the mediated character of every act of conferring and understanding meaning.

3 Bruno Latour's Actor-Network Theory was developed as a rival to this sociological approach to technology, known as the "Social Construction of Technology" ( ferral of meaning connected with technology, but also, and above all, attributed a directive role to the technological artifacts themselves. There are thus several rival theories at work here. See Bijker (1995 $\left.{ }^{\mathrm{a}}\right)$ and Latour $\left(1993^{\mathrm{a}}, 1993^{\mathrm{b}}\right)$.

4 See also Crosby (1997).

5 The connection between Renaissance perspectivism and the current environmental crisis was made in the Netherlands by Ton Lemaire (1970). Although I do not share the pessimism of his diagnosis, my interest in the subject was aroused by this exemplarybook.

6 Rembrandt painted two anatomical lessons. The Anatomical Lesson of Dr Deijman was later damaged by fire in the anatomy theatre in the Weigh house (Waag) in Amsterdam. Since the organisation of an anatomical lesson involved expenses, people had to pay to attend it. A 1625 ruling fixed the rate at 6 stuivers per corpse for members of the guild, irrespective of the number of days that a lesson lasted, and 4 stuivers for outsiders. The Anatomy Book of the Guild of Surgeons records that the anatomical lesson of Dr Deijman in January 1656, which lasted three days, raised the sum of 187 guilders and 6 stuivers. Although it is impossible to determine the precise number, this seems to indicate that between two and three hundred people came to watch in the dissecting room every day! (Middelkoop 1994, 11).

7 For incisive criticism of Crary's philosophical digressions, see Atherton (1996, 139-165), Batchen (1991).

8 See Jay $(1988,3-23)$.

9 Foucault (1976), Zwart (1995). See also the comments on this by Schermer (1996, 81-85).

10 From Hankins and Silverman $(1995,171)$. 